\title{
Penentuan Distribusi Sample Terbatas Uji-J Davidson dan Mackinnon dengan Metode Bootstrap pada Model Regresi Tak Tersarang
}

\author{
Georgina Maria Tinungki*
}

\begin{abstract}
There are some tests proposed for un-nested hypothesis between J-Davidson Test and MacKinnon Test. J's Test is often bad result, but it always works very well when used bootstrap. Bootstrapping for J's Test is expected to be able to show that by using bounded sample is better, because there is no fault in counting process. Moreover, bootstrapping J-Test will omit the possibility of inconsistence of the results test previously. Simulation result of Monte Carlo will compare the proposed bounded sample test with Cox and J's Test previously.
\end{abstract}

Keywords: un-nested hypothesis, J-Davidson Test, MacKinnon Test

\begin{abstract}
Abstrak
Terdapat beberapa pengujian yang diusulkan untuk hipotesis tak tersarang antara lain Uji-J Davidson dan MacKinnon. Uji-J sering bekerja buruk, tetapi biasanya bekerja sangat baik ketika dibootstrapkan.. Bootstrapping Uji-J diharapkan mampuh menunjukkan sampel terbatas lebih baik karena tidak mempunyai kesalahan didalam proses perhitungan. Lebih dari itu, bootstrapping J-Tests akan mengeluarkan kemungkinan dari ketidak konsistenan hasil uji yang sebelumnya. Hasil Simulasi Monte Carlo membandingkan uji sampel terbatas yang diusulkan dengan test yang sebelumnya seperti Uji Cox dan J-Test.
\end{abstract}

Kata Kunci: Hipotesis tak tersarang, Uji-J Davidson, Uji MacKinnon

\section{Pendahuluan}

Hipotesis taktersarang (Non nested Hypotesis), pertama kali diperkenalkan oleh Cox (1961, 1962) yang disebut Uji Cox dan dikembangkan lebih lanjut oleh Pesaran (1974) serta Pesaran dan Dalton (1978). Uji Cox memiliki beberapa kekurangan yaitu tidak dapat diterapkan pada asumsi distribusional karena ketidak akuratan pada hasil ujinya dan jumlah sampelnya terbatas (jumlahnya tidak diketahui dengan pasti).

Uji J untuk model regresi taktersarang, merupakan pengujian dua langkah berdasarkan 'artificial nesting (tiruan tersarang), dimana uji J cenderung lebih mudah dan praktis ketimbang uji Cox, namun hasil ujinya masih belum akurat sebagaimana pada uji Cox. Selain distribusi asimptotik, juga tampilan sampel kecil pada uji J dianggap tidak memuaskan.

Fan\&Li(1995) dan Godfrey(1997) menyarankan bootstrapping uji J dan berhasil meningkatkan kekuatan pada sampel terbatasnya. Metode ini juga memudahkan dalam menghitung statistic uji dan sangat mudah dilakukan. Dalam tulisan ini, hasil eksperimen Monte Carlo dengan bootstrapping Uji $\mathrm{J}$ bekerja sangat baik, meskipun uji ini tidak berdasarkan pengulangan yang cukup untuk menjadi defenitif.

Pada Uji J dibootstrapkan dengan menggunakan simulasi Monte Carlo, diperoleh hasil yang sangat akurat, karena mampu menggunakan pengulangan-pengulangan dengan biaya yang rendah.

*Jurusan Matematika

Fakultas Matematika dan Ilmu Pengetahuan Alam

Universitas Hasanuddin Makassar

ina_matematika@yahoo.co.id 


\section{Kajian Teori}

Nilai parameter regresi $\beta$ belum dikteahui nilainya, sehingga pemodelan regresi, diasumsikan bahwa bentuk $\varepsilon=Y-X \beta$ bersifat acak, dimana $E\left(\varepsilon_{1}\right)=0$

dan $\operatorname{Var}\left(\varepsilon_{1}\right)=\sigma^{2}$ sehingga errornya tidak saling berkorelasi untuk setiap $i=1,2, \ldots \ldots ., n$

Jika $\hat{\beta}_{0}$ dan $\hat{\beta}_{1}$ merupakan penaksir dari parameter $\beta_{0}$ dan $\beta_{1}$, maka dengan menggunakan metode kuadrat terkecil penaksir tersebut dapat diperoleh dengan meminimumkan bentuk kuadrat error:

$J=\sum_{i=1}^{n} \varepsilon_{i}^{2}=\sum_{i=1}^{n}\left(Y_{i}-\beta_{0}-\beta_{1} X_{i}\right)^{2}$

Supaya J minimum, maka $\frac{\partial J}{\partial \beta_{0}}=0$ dan $\frac{\partial J}{\partial \beta_{1}}=0$

Jadi, bila J diturunkan terhadap $\beta_{0}$, maka diperoleh:

$$
\frac{\partial J}{\partial \beta_{0}}=-2 \sum_{i=1}^{n}\left(Y_{i}-\beta_{0}-\beta_{1} X_{i}\right)=0
$$

atau,

$$
\sum_{i=1}^{n} Y_{i}-n \beta_{0}-\beta_{1} \sum_{i=1}^{n} X_{i}=0
$$

Selanjutnya, turunkan $\mathrm{J}$ terhadap $\beta_{1}$, maka diperoleh:

$$
\frac{\partial J}{\partial \beta_{1}}=-2 \sum\left(Y_{i}-\beta_{0}-\beta_{1} X_{i}\right) X_{i}=0
$$

atau,

$$
\sum_{i=1}^{n} Y_{i} X_{i}-\beta_{0} \sum_{i=1}^{n} X_{i}-\beta_{1} \sum_{i=1}^{n} X_{i}^{2}=0
$$

Selanjutnya, mengganti $\beta_{0}$ dan $\beta_{1}$ dengan penaksirnya $\hat{\beta}_{0}$ dan $\hat{\beta}_{1}$ sehingga diperoleh:

$$
\begin{aligned}
& \sum_{i=1}^{n} Y_{i}=n \hat{\beta}_{0}+\hat{\beta}_{1} \sum_{i=1}^{n} X_{i} \\
& \sum_{i=1}^{n} Y_{1} X_{i}=\hat{\beta}_{0} \sum_{i=1}^{n} X_{i}+\hat{\beta}_{1} \sum_{i=1}^{n} X_{i}^{2}
\end{aligned}
$$

Persamaan (5) dan (6) dinamakan persamaan normal yang dapat ditulis dalam bentuk matriks sebagai berikut:

$$
X^{T} X \hat{\beta}=X^{T} Y
$$

Dimana $X^{T}=\left[\begin{array}{ccccc}1 & 1 & \cdot & \cdot & 1 \\ X_{1} & X_{2} & \cdot & \cdot & X_{n}\end{array}\right]$ maka diperoleh

$$
X^{T} X=\left[\begin{array}{ll}
n & \sum_{i=1}^{n} X_{i} \\
\sum_{i=1}^{n} X_{i} & \sum_{i=1}^{n} X_{i}^{2}
\end{array}\right] \text { dan }
$$




\section{Georgina Maria Tinungki}

$$
X^{T} Y=\left[\begin{array}{ccccc}
1 & 1 & \cdot & \cdot & 1 \\
X_{1} & X_{2} & \cdot & \cdot & X_{n}
\end{array}\right]\left[\begin{array}{l}
Y_{1} \\
Y_{2} \\
Y_{3} \\
\cdot \\
\cdot \\
Y_{n}
\end{array}\right]=\left[\begin{array}{l}
\sum_{i=1}^{n} Y_{i} \\
\sum_{i=1}^{n} X_{i} Y_{i}
\end{array}\right]
$$

Karena matriks $X^{T} X$ tidak singular sehingga persamaan normal mempunyai penyelesaian tunggal :

$$
\hat{\beta}=\left(X^{T} X\right)^{-1} X^{T} Y
$$

\section{Hipotesis Nested}

Dua model dikatakan nested jika salah salah satu model dapat direduksi menjadi model lainnya dengan memberlakukan batasan pada parameter Misalkan,uji hipotesis model regresi nested berikut:

$$
\begin{aligned}
& H o: \beta o+\beta_{1} X_{1}+\beta_{2} X_{2} \quad+\varepsilon_{0} \\
& H_{1}: \beta o+\beta_{1} X_{1}+\beta_{2} X_{2}+\beta_{3} X_{3}+\varepsilon_{1}
\end{aligned}
$$

adalah model tersarang(nested) karena dengan menggunakan batasan $\beta_{3}=0$ maka $H_{1}$ dapat menjadi $H_{0}$. Dengan kata lain $H_{1}$ mencakup $H_{0}$. Perbadaan kedua model model ini meliputi batasan pada $\beta_{3}$.Kasus ini dapat diselasaikan dengan uji-t berdasarkan OLS dan uji rasio Likelihood.

\section{Hipotesis Nonnested}

Dua model dikatakan taktersarang(non-nested) jika salah satu model tidak dapat direduksi menjadi model lain dengan memberlakukan pembatasan pada parameter Misalnya, 2 hipotesis nonnested berikut:

$H o: \beta o+\beta_{1} X_{1}+\beta_{2} X_{2}+\beta_{3} X_{3}+\varepsilon_{0}$

$$
H_{1}: \beta o+\quad+\beta_{3} X_{3}+\beta_{4} X_{4}+\beta_{5} X_{5}+\varepsilon_{1}
$$

Dikatakan non-nested karena jika memberlakukukan batasan $\beta_{4}=0$ dan $\beta_{5}=0$ maka $H_{1}$ tidak dapat menjadi $H_{0}$

\section{Uji untuk Model Hipotesis Nonnested}

\section{Uji Cox}

Dua model hipotesis Nonnested dalam bentuk matrik:

$$
\begin{aligned}
& H_{0}: y=X \beta+\varepsilon_{0} \\
& H_{1}: y=Z \gamma+\varepsilon_{1}
\end{aligned}
$$

Dimana y adalah vektor $(\mathrm{n} \times 1)$ dari variabel terikat, $\mathrm{X}$ dan $\mathrm{Z}$ masing-masing adalah regresi matrix $\left(\mathrm{nxk}_{1}\right)$ dan $\left(\mathrm{nxk}_{2}\right), \varepsilon_{0}$ dan $\varepsilon_{1}$ adalah vektor error $(\mathrm{nx} 1)$. Anggap bahwa $\mathrm{E}\left(\varepsilon_{0}\right)=\mathrm{E}\left(\varepsilon_{1}\right)=0$ dan $\operatorname{var}\left(\varepsilon_{0}\right)=. \sigma_{1}^{2} I \operatorname{var}\left(\varepsilon_{1}\right)=\sigma_{2}^{2} I$. Selain itu, juga asumsikan dua alternatif perangkat regresor, $\mathrm{X}$ dan $\mathrm{Z}$, mungkin memiliki beberapa variabel umum, namun tidak satupun yang merupakan 


\section{Georgina Maria Tinungki}

sub perangkat bagi yang lain. Masalahnya ialah untuk memutuskan model mana yang lebih baik.

Cox $(1961,1962)$ mengembangkan varian pengujian ratio kemungkinan untuk hipotesis nonnested. Pesaran (1974), Pesaran\&Deaton (1978), dan McAleer (1984) memperoleh berbagai versi pengujian Cox untuk kasus-kasus regresi. Untuk hipotesis (1) dan (2), statistik Cox untuk pengujian, bahwa $\mathrm{H}_{0}$ benar dan $\mathrm{H}_{1}$ tidak.

$$
c_{12}=\frac{n}{2} \log \left[\frac{S_{z}^{2}}{S_{Z X}^{2}}\right]
$$

Dimana

$$
S_{Z}^{2}=\hat{v}^{\prime} \hat{v} / n, S_{Z X}^{2}=S_{X}^{2}+(1 / n) \hat{\beta}^{\prime} X^{\prime} M_{Z} X \hat{\beta}, \hat{\beta}=\left(X^{\prime} X\right)^{-1} X^{\prime} y \text {, dan } M_{Z}=1-Z\left(Z^{\prime} Z\right)^{-1} Z^{\prime}
$$

Statistik pengujian dari uji Cox adalah sebagai berikut.

$$
\frac{c_{12}}{S E\left(c_{12}\right)}=\frac{c_{12}}{\sqrt{\frac{s_{x}^{2}\left(\hat{\beta}^{\prime} X^{\prime} M_{z} M_{x} M_{z} X \hat{\beta}\right)}{s_{z x}^{4}}}}
$$

Dimana $M_{x}=1-X\left(X^{\prime} X\right)^{-1} X^{\prime}$.Cox telah menunjukkan bahwa statistik pengujian pada persamaan (12) merupakan suatu variabel normal standar di bawah $\mathrm{H}_{0}$. Secara signifikan nilai statistik yang lebih besar dari nol merupakan bukti menolak $\mathrm{H}_{0}$.

\section{Uji J}

Uji J yang diusulkan oleh Davidson dan MacKinnon (1981) merupakan versi yang dilinearkan pada uji Cox dengan menggunakan model "tersarang tiruan" sebagai berikut

$$
y=(1-\lambda) X \beta+\lambda Z \gamma+\varepsilon
$$

Jika model diestimasi dengan menguji salah satu parameter yaitu $\lambda=0$ maka menolak hipotesis $\mathrm{H}_{0}$ dan jika $\lambda=1$ maka dapat menerima hipotesis $\mathrm{H}_{1}$. Namun yang menjadi kendala adalah $\lambda$ tidak teridentifikasi pada estimasi persamaan (13). Davidson dan MacKinnon (1981) menyarankan prosedur dua langkah: $\gamma$ diestimasi oleh nilai terkecil dari persamaan (10), dan penaksir, $\hat{\gamma}$, digantikan untuk $\gamma$ yang tidak diketahui pada persamaan (13) untuk memperkirakan $\lambda$ secara terpisah. Dengan demikian pada tahap kedua, persamaan berikut diestimasi dengan nilai terkecil.

$$
y=(1-\lambda) X \beta+\lambda(Z \hat{\gamma})+\varepsilon
$$

Dimana $\hat{Y}_{z}=Z \hat{\gamma}$, sehingga persamaan menjadi:

$$
y=(1-\lambda) X \beta+\lambda \hat{Y}_{Z}+\varepsilon
$$

Dengan cara yang sama pada persamaan (10), $\hat{\beta}$ diestimasi dan mengganti $X \beta$ pada persamaan (14) dengan $X \hat{\beta}$ atau $\hat{Y}_{X}$. Persamaannya menjadi:

$$
y=(1-\lambda) \hat{Y}_{X}+\lambda \hat{Y}_{Z}+\varepsilon
$$

Uji J Davidson \& Mckinnon menggunakan uji-t untuk mengestimasi koefisien $\hat{Y}_{Z}$ pada persamaan (15) dan $\hat{Y}_{X}$ persamaan(16). Statistik-t pada koefisien $\hat{Y}_{Z}$ menolak $\mathrm{H}_{0}$ sesuai model dan nilai signifikan statistik-t pada hasil koefisian $\hat{Y}_{X}$ adalah penolakan terhadap $\mathrm{H}_{1}$. Kedua hasil statistic-t mmperlihatkan penolakan tiap model.. Sebagian regresor ada persamaan in (15) and (16)merupakan stokastik,uji $t$-test sebagian tidak valid. 


\section{Georgina Maria Tinungki}

Statistik uji-t untuk signifikansi $\lambda$ pada persamaan(15),seperti pengambilan keputusan pada hipotesis (9) tergantung pada kecocokan nilai regresi $\mathrm{Y}$ terhada $Z$ ', kecocokan data pada regresi (15) seperti halnya korelasi antara dua himpunan dari regresor (15).Dengan melihat penggunaan $\mathrm{F}$ rasio untuk menguji $\lambda=0$ yang sama pada nilai t kuadrat ketika ditarik dari kontribusi salah satu regresor $\hat{Y}_{Z}$. Dengan cara yang sama dapat diaplikasikan pada signifikansi (1- $\lambda$ ) pada persamaan (16).

Dengan asumsi hipotesis $\lambda=0$, maka statistik uji $\mathrm{F}$ adalah:

$$
{ }^{2} F\left(1, T-k_{1}-1\right)=\frac{\left(1, T-k_{1}-1\right)\left[R_{Y Z}-R_{Y X} \cdot R_{\hat{Y} X} R_{\hat{Y} Z}\right]^{2}}{\left(1-R_{Y X}^{2}\right)\left(1-R_{\hat{Y} X}^{2}\right)-\left[R_{Y Z}-R_{Y X} R_{\hat{Y} X \hat{Y} Z}\right]^{2}}
$$

Karena uji J adalah simetrik,kedua bagian uji J,mencakup (10) dan sigifikansi (1- $\lambda$ )pada persamaan (16) statistik uji dinotakan sebagai ${ }^{1} \mathrm{~F}$ sabagai berikut:

$$
{ }^{1} F\left(1, T-k_{1}-1\right)=\frac{\left(1, T-k_{2}-1\right)\left[R_{Y X}-R_{Y Z} \cdot R_{\hat{Y} X} R_{\hat{Y} Z}\right]^{2}}{\left(1-R_{Y Z}^{2}\right)\left(1-R_{\hat{Y} Z}^{2}\right)-\left[R_{Y X}-R_{Y Z} R_{\hat{Y} X \hat{Y} Z}\right]^{2}}
$$

Ketika ukuran sample kecil,perbedaan antara jumlah dari regresor dalam model yang saling bersaing, akan mempengaruhi ukuran pada uji statistiknya.jika data telah diperoleh dari model (9), statistic uji ${ }^{1} \mathrm{~F}$ akan menjadi kecil seperti jumlah regresor pada model, $\mathrm{k}_{2}$, meningkat.. Hal ini akan semakin mendorong kea rah penolakan $\mathrm{H}_{0}$, sebaliknya penerimaan $\mathrm{H}_{1}$ jika jumlah regresor $\mathrm{k}_{1}$ kecil.kekonsistenan ini,Godfrey dan pesaran (1982) menemukan simulation-based seperti halnya Gourieroux dan Monfort (1994) yang menyimpulkan bahwa uji ini sangat sensitive terhadap relative jumlah regresor pada dua hipotesis . Kekuatan uji $\mathbf{J}$ sangat lemah ketika jumlah regresor dalam $\mathrm{H}_{0}$ lebih kecil dari jumlah regresor dalam $\mathrm{H}_{1}$

\section{Bootstrapping Uji J}

Metode bootstrap pertama kali diperkenalkan oleh Bradley Efron pada tahun 1979.Istilah bootstrap berasal dari "pull one self upby one's bootstrap" yang berarti berpijak di atas kaki sendiri, berusaha dengan sumber daya yang minimal.Dalam sudut pandang statistika, sumber daya minimal adalah jumlah data yang sedikit, data yang menyimpang dari asumsi tertentu atau data yang tidak mempunyai asumsi apapun tentang distribusi populasinya.

Dalam kasus ini, statistik uji bootstrap diberi simbol $\hat{\tau}$ yang dapat dihitung dengan cara biasa. Dengan membandingkan nilai kritis dari beberapa distribusi teoritis, dapat diambil keputusan menerima atau menolak hipotesis nol dengan melihat nilai $\hat{\tau}$ dari distribusi yang diestimasi pada sejumlah besar statistik uji bootstrap yang dihitung dengan simulasi data. Dengan berasumsi normal, akan membatasi tulisan ini pada uji bootstrap parametrik.

Terdapat beberapa cara untuk uji hipotesis bootstrap..Di dalam pandangan umum, cara paling mudah dan paling yang informatif untuk menggunakan bootstrap pada beberapa uji hipotesis adalah menghitung nilai bootstrap P; untuk metoda yang lainnya, lihat Horowitz (1994). Adapun prosedur kerja bootstrap adalah sebagai berikut:

a. Menaksir $\mathrm{H}_{0}$ dengan OLS, kemudian memperoleh $\hat{\tau}$ untuk menaksir parameter $\hat{\beta}$ dan $s^{2}$

b. Nilai B pada error bootstrap $\varepsilon_{j}^{*}$ dari distribusi $\mathrm{N}\left(0 ; \mathrm{s}^{2}\right)$ dengan menggunakan parameter estimasi $\hat{\beta}$ untuk menghasilkan sample bootstrap $\mathrm{B} y_{j}^{*}, j=1, \ldots ., B$, dengan persamaan:

$$
y_{j}^{*}=X \hat{\beta}+\varepsilon_{j}^{*}
$$


c. Menggunakan setiap sampel ini untuk menghitung statistic uji $\tau_{j}^{*}$ dengan cara sama pada $\hat{\tau}$ yang dihitung dari sample yang sebenarnya.Kemudian menghitung taksiran nilai $\mathrm{P}$ bootstrap

$$
\hat{p}^{*}(\hat{\tau})=\frac{1}{B} \sum_{j=1}^{B} I\left(\tau_{j}^{*} \geq \hat{\tau}\right)
$$

di mana I(.) adalah satu fungsi indikator, setara dengan 1 jika pernyataannya benar dan 0 lainnya dengan asumsi uji $\mathbf{J}$ adalah uji satu arah.Di dalam prosedur hanya menggambarkan $\mathrm{B}$ bisa bernilai integer positif yang terpilih sehingga $\alpha(B+1)$ adalah satu integer, di mana $\alpha$ adalah ukuran uji yang diinginkan. B bernilai besar membuat hasil tes sedikit bebas dari penggunaan sample bootstrap dan semakin meningkatkan kekuatan ujinya.(Davidson dan MacKinnon (1997b)). Kecuali jika dalam perhitungan biayanya adalah suatu masalah, maka disarankan menggunakan sedikitnya $\mathrm{B}=999$, terutama nilai yang lebih besar dalam penerapannya. Monte Carlo mengadakan percobaan, bagaimanapun, nilai-nilai lebih kecil dari B bekerja dengan baik, karena error cenderung ke luar dari pengulangan-pengulangan. Di dalam bagian yang berikutnya, kita akan menggunakan $B=399$ di dalam percobaan ini. Taksiran bootstrap dari nilai kritis $\alpha$ akan dibiaskan kapan pun nilai kritis yang bergantung pada parameter non linear. Tingkat bias tergantung pada varians dari parameter taksirannya.Bias akan semakin besar jika nilai variansi meningkat. Dalam kedua kasus ini, yang penting adalah bentuk dari "fungsi nilai kritis," yang berhubungan dengan nilai kritis untuk uji tertentu yang menghubungkan dengan nilai parameternya.

\section{Hasil Penelitian dan Pembahasan}

Berdasarkan data hasil simulasi Jaringan Neural (A.Elazouni I.Nosair., Journal O Computing in Civil Engenering) yang terdiri dari 8 sampel, 7 variabel independen dan 1 variabel dependen.

Analisis lebih lanjut, akan digunakan Software SPSS dan Matlab 7.0.1

\section{Penentuan Hipotesis Nonnested Untuk Sampel 20 \\ Analisis Regresi Untuk Ho}

\section{Tabel 1 : Coefficient}

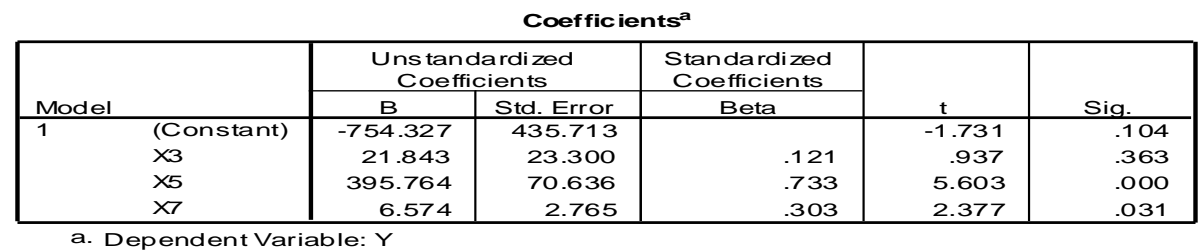

Dari tabel 1 diperoleh persamaan : $\mathrm{Y}=-754.40+21.843 \mathrm{X}_{3}+395.81 X_{5}+6.56 X_{7}$

Tabel 2 : Model Summary

Model Summary

\begin{tabular}{|l|r|r|r|r|}
\hline Model & $\mathrm{R}$ & R Square & $\begin{array}{c}\text { Adjusted } \\
\text { R Square }\end{array}$ & $\begin{array}{r}\text { Std. Error of } \\
\text { the Estimate }\end{array}$ \\
\hline 1 & $.887^{\mathrm{a}}$ & .787 & .745 & 299.394 \\
\hline
\end{tabular}

a. Predictors: (Constant), X7, X3, X5

Dari table 2 terlihat nilai R Square 0.79 dan estimasi standar error 299.40 


\section{Georgina Maria Tinungki}

\section{Hipotesis Nonnested:}

$\mathrm{H}_{0}$ : Tidak ada pengaruh jumlah beton yang diperlukan per hari, tinggi, tingkat dorongan pada slipform dan jumlah konstruksi bangunan terhadap kualitas beton dalam bentuk persamaan $\mathrm{Y}=-754.40+21.843 \mathrm{X}_{3}+395.81 X_{5}+6.56 X_{7}$

$\mathrm{H}_{1}$ : Ada pengaruh jumlah bak, jumlah beton yang diperlukan per hari dan tingkat dorongan pada slipform terhadap kualitas beton dalam bentuk persamaan $\mathrm{Y}=1855.21+38.17 X_{1}-35.96 X_{2}-377.45 X_{4}$

\section{Hasil Uji J dan Bootstrapping Uji J}

Dari dua persamaan hipotesis nonnested di atas akan digunakan uji J dan Bootstrap untuk memperoleh persamaan yang terbaik. Dengan bantuan Matlab 7.0.1, akan diperoleh hasil sebagai berikut:

Tabel 3 : Hasil Output Uji J dan Bootstraping Uji J $\alpha=0.01$

\begin{tabular}{|c|c|c|c|c|c|c|c|c|c|c|}
\hline \multirow{2}{*}{\multicolumn{2}{|c|}{ Test }} & \multirow[b]{2}{*}{ Sampel } & \multicolumn{4}{|c|}{ Pengujian $\mathrm{H}_{0}$} & \multicolumn{4}{|c|}{ Pengujian $\mathrm{H}_{1}$} \\
\hline & & & $R_{Y X}^{2}$ & $\overline{D f}$ & $F_{1}$ & Kesp & $R_{Y Z}^{2}$ & $\mathrm{df}$ & $\mathrm{F}_{2}$ & Kesp \\
\hline \multicolumn{2}{|l|}{ Uji J } & 20 & 0.7886 & 16 & 9.4536 & ditolak & 0.7930 & 16 & 9.1414 & ditolak \\
\hline \multirow{2}{*}{$\begin{array}{c}\text { Bootstrap } \\
\text { J }\end{array}$} & 399 & 20 & 0.7101 & 16 & 29.8145 & ditolak & 0.8593 & 16 & 7.3883 & Diterima \\
\hline & 999 & 20 & 0.7054 & 16 & 12.4875 & ditolak & 0.8299 & 16 & 5.4211 & Diterima \\
\hline
\end{tabular}

Dari output Uji J dan Bootstraping Uji J pada Tabel 3 terlihat bahwa :

1. Pada Uji J untuk ukuran sampel 20 terlihat hasil pengujian $\mathrm{H}_{0}$ adalah $R_{Y X}^{2}=0.7886$, jumlah derajat bebas atau $\mathrm{df}=16$ serta nilai $\mathrm{F}_{1}=9.436>\mathrm{F}_{0.01(1,16)}=8.53$. Hasil pengujian $\mathrm{H}_{1}$ adalah $R_{Y Z}^{2}=0.7930$, jumlah derajat bebas atau df $=16$ dan nilai $\mathrm{F}_{2}=9.1414>\mathrm{F}_{0.01(1,16)}=8.53$. Dari kedua hasil tidak pengujian tidak dapat diambil kesimpulan karena kedua-duanya menolak hipotesis.

2. Pada Uji Bootstrap untuk ukuran sampel 20 akan dilakukan replikasi sebanyak 2 kali, yaitu replikasi 399 dan 999. Pada replikasi 399 sudah ada kesimpulan yaitu menolah $\mathrm{H}_{0}$ dan menerima $\mathrm{H}_{1}$. Hal ini terlihat dari $F_{1}^{*}=29.8145>\mathrm{F}_{0.01(1,16)}=8.53$, dengan $\mathrm{H}_{1}$ atau $F_{2}^{*}=7.3883$ $<\mathrm{F}_{0.01(1,16)}=8.53$. Begitupula terlihat pada replikasi 999, nilai $F_{1}^{*}=12.4875>\mathrm{F}_{0.01(1,16)}=8.53$ dan $F_{2}^{*}=5.4211<\mathrm{F}_{0.01(1,16)}=8.53$. Artinya ada pengaruh jumlah beton yang diperlukan per hari, tinggi, tingkat dorongan pada slipform dan jumlah konstruksi bangunan terhadap kualitas beton dalam bentuk persamaan $\mathrm{Y}=-754.327+21.843 \mathrm{X}_{3}+395.764 X_{5}+6.574 X_{7}$.

\section{Penentuan Hipotesis Nonnested Untuk Sampel 35}

\section{Tabel 4 : Coefficient}

Coefficients $^{a}$

\begin{tabular}{|ll|r|r|r|r|r|}
\hline \multirow{2}{*}{ Model } & \multicolumn{2}{|c|}{$\begin{array}{c}\text { Uns tandardized } \\
\text { Coefficients }\end{array}$} & \multicolumn{2}{c|}{$\begin{array}{c}\text { Standardized } \\
\text { Coefficients }\end{array}$} & & \\
\cline { 3 - 5 } & & \multicolumn{1}{|c|}{$\mathrm{B}$} & Std. Error & \multicolumn{1}{|c|}{ Beta } & \multicolumn{1}{c|}{$\mathrm{T}$} & \multicolumn{1}{c|}{ Sig. } \\
\hline 1 & (Constant) & 443.269 & 726.573 & & .610 & .546 \\
& X2 & 74.340 & 33.526 & .233 & 2.217 & .034 \\
& X3 & 47.437 & 10.186 & .408 & 4.657 & .000 \\
& X4 & -332.514 & 125.184 & -.286 & -2.656 & .013 \\
& X5 & 365.498 & 53.287 & .560 & 6.859 & .000 \\
\hline
\end{tabular}

a. Dependent Variable: $Y$ 
Georgina Maria Tinungki

Dari Tabel 4 diperoleh persamaan

$Y=443.27+74.34 X_{2}+47.45 X_{3}-332.52 X_{4}+365.49 X_{5}$

\section{Tabel 5 : Model Summary}

Model Summary

\begin{tabular}{|l|r|r|r|r|}
\hline Model & R & R Square & $\begin{array}{c}\text { Adjusted } \\
\text { R Square }\end{array}$ & $\begin{array}{c}\text { Std. Error of } \\
\text { the Estimate }\end{array}$ \\
\hline 1 & $.898^{\mathrm{a}}$ & .807 & .781 & 270.116 \\
\hline
\end{tabular}

a. Predictors: (Constant), $\times 5, \times 2, \times 3, \times 4$

Dari Tabel 5 terlihat nilai R Square 0.807 dan estimasi standar error 270.12

\section{Analisis Regresi Untuk Ho}

Tabel 6 : Coefficient

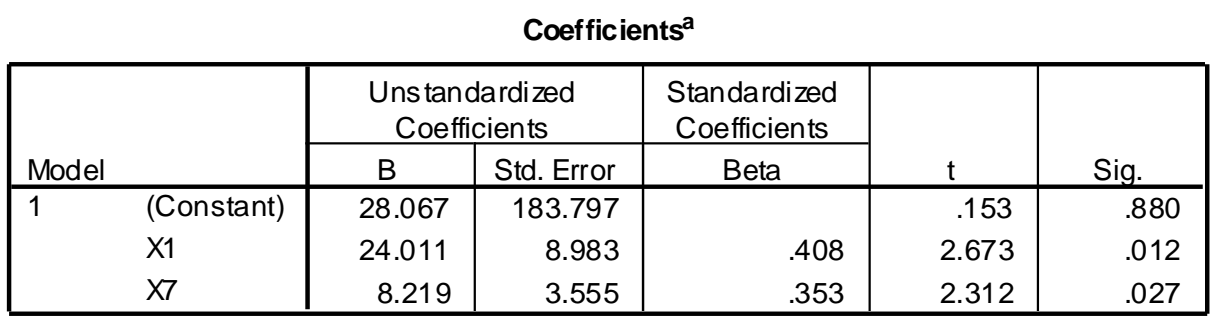

a. Dependent Variable: $Y$

Dari Tabel 6 diperoleh persamaan $Y=28.07+24.01 X_{1}+8.22 X_{7}$

\section{Tabel 7 : Model Summary}

Model Summary

\begin{tabular}{|l|r|r|r|r|}
\hline Model & $\mathrm{R}$ & R Square & $\begin{array}{c}\text { Adjusted } \\
\text { R Square }\end{array}$ & $\begin{array}{r}\text { Std. Error of } \\
\text { the Estimate }\end{array}$ \\
\hline 1 & $.656^{\mathrm{a}}$ & .430 & .395 & 449.186 \\
\hline
\end{tabular}

a. Predictors: (Constant), X7, X1

\section{Hipotesis Nonnested:}

$\mathrm{H}_{0}$ : Tidak ada pengaruh tinggi, jumlah konstruksi bangunan, jumlah pengangkatan dorongan terhadap kualitas beton dalam bentuk persamaan $Y=443.269+74.340 X_{2}+47.437 X_{3}-332.514 X_{4}+365.498 X_{5}$

$\mathrm{H}_{1}$ : Ada pengaruh jumlah bak, dan jumlah pengangkatan dorongan terhadap kualitas beton bentuk persamaan $Y=28.067+24.011 X_{1}+8.219 X_{7}$

\section{Hasil Uji J dan Bootstrapping Uji J}

Dari dua persamaan hipotesis nonnested di atas akan digunakan uji $\mathbf{J}$ dan Bootstrap untuk memperoleh persamaan yang terbaik. Dengan bantuan Matlab 7.0.1, akan diperoleh hasil sebagai berikut:

Tabel 8 : Hasil Output Uji J dan Bootstraping Uji J $\alpha=0.01$

\begin{tabular}{|c|c|c|c|c|c|c|c|c|c|}
\hline \multirow{2}{*}{ Test } & \multirow{3}{*}{ Sampel } & \multicolumn{4}{|c|}{ Pengujian $\mathbf{H}_{\mathbf{0}}$} & \multicolumn{4}{c|}{ Pengujian $\mathbf{H}_{\mathbf{1}}$} \\
\cline { 3 - 11 } & $R_{Y X}^{2}$ & df & $\mathrm{F}_{1}$ & Kesp & $R_{Y Z}^{2}$ & df & $\mathrm{F}_{2}$ & Kesp \\
\hline
\end{tabular}


Georgina Maria Tinungki

\begin{tabular}{|c|l|l|c|c|c|c|c|c|c|c|}
\hline \multicolumn{2}{|c|}{ Uji J } & $\mathbf{3 5}$ & 0.8069 & 30 & 11.6951 & ditolak & 0.4303 & 32 & 112.5150 & ditolak \\
\hline \multirow{2}{*}{$\begin{array}{c}\text { Bootstrap } \\
\text { J }\end{array}$} & $\mathbf{3 9 9}$ & $\mathbf{3 5}$ & 0.5202 & 30 & 7.8726 & ditolak & 0.4561 & 32 & 8.6489 & ditolak \\
\cline { 2 - 11 } & $\mathbf{9 9 9}$ & $\mathbf{3 5}$ & 0.7686 & 30 & 7.5248 & diterima & 0.3109 & 32 & 40.2749 & ditolak \\
\hline
\end{tabular}

Dari output Uji J dan Bootstraping Uji J pada Tabel 8 terlihat bahwa :

3. Pada Uji J untuk ukuran sampel 35 terlihat hasil pengujian $\mathrm{H}_{0}$ adalah $R_{Y X}^{2}=0.8069$, jumlah derajat bebas atau $\mathrm{df}=30$ serta nilai $\mathrm{F}_{1}=11.6951>\mathrm{F}_{0.01(1,30)}=7.56$. Hasil pengujian $\mathrm{H}_{1}$ adalah $R_{Y Z}^{2}=0.4303$, jumlah derajat bebas atau $\mathrm{df}=32$ dan nilai $\mathrm{F}_{2}=112.515>\mathrm{F}_{0.01(1,30)}=7.56$. Dari kedua hasil tidak pengujian tidak dapat diambil kesimpulan karena kedua-duanya menolak hipotesis.

4. Pada Uji Bootstrap untuk ukuran sampel 35 akan dilakukan replikasi sebanyak 2 kali, yaitu replikasi 399 dan 999. Pada replikasi 399 sudah belum ada kesimpulan karena kedua-duanya ditolak. Hal ini terlihat dari $F_{1}{ }^{*}=7.88>\mathrm{F}_{0.01(1,30)}=7.56$, dengan $\mathrm{H}_{1}$ atau $F_{2}{ }^{*}=8.65>\mathrm{F}_{0.01(1,30)}=7.56$ dan pada replikasi 999 , nilai $F_{1}{ }^{*}=7.53<\mathrm{F}_{0.01(1,30)}=7.56$ dan $F_{2}^{*}=40.28>\mathrm{F}_{0.01(1,30)}=7.56$. Artinya kualitas beton hanya dipengaruhi oleh jumlah bak dan jumlah pengangkutan dorongan yang ditulis dalam bentuk persamaan $Y=28.07+24.01 X_{1}+8.22 X_{7}$.

\section{Simpulan}

- Dengan menggunakan metode Bootstrapping J akan menghasilkan sebuah model yang memiliki tingkat signifikan lebih tinggi.

- Uji J tidak efektif digunakan dalam menentukan model terbaik suatu hipotesis nonnested karena ketidakkonsistenan hasil ujinya pada jumlah sample terbatas.

- Uji Bootstrap dapat mengatasi ketidakkonsistenan yang terjadi pada uji J karena bootstrap mampu menyelesaikan permasalahan yang memiliki jumlah sampel terbatas.

\section{Daftar Pustaka}

[1]. Bain, L.J and Max Engelhardt, 1992. Introduction to Probability and Mathematical Statistics.Duxbury

[2]. Davidson Russel, 1997. Bootstrap Tests of Nonnested Linear regression Models, Canada,Ontario,Kingston

[3]. Jeong Jinook, 2006. " $R^{2}$-based bootstrap Tests for Nonnested Hypotheses in Regression Models,"Department of Economics, Yonsei University

[4]. James G.MacKinnon, 1999. Bootstrap Testing in Econometrics, Queen's University at Kingston

[5]. Hashem Pesaran, M dan Melvyn Weeks., 1999. Non-nested Hypotesis testing:An Overview, Faculty of Economics and Politic,University of Cambrige.

[6]. Abdul Halid Nusi., 2005. Metode Bootstrap Nonparametrik Pada Model Regresi Linear: Skripsi, Fakultas Matematika dan Ilmu Pengetahuan Alam,Universitas Hasanuddin. 